\title{
Arbor
}

\section{Estado de la cuestión en materia de literatura en España en el cambio de siglo}

\section{Abraham Madroñal}

Arbor CLXVIII, 664 (Abril 2001), 623-640 pp.

Hemos tratado de hacer un ligero bosquejo de cómo están las cosas en materia filológica, en lo que afecta a los géneros narrativo y poético, tanto desde el punto de vista editorial como en el de loş estudios desde cualquier óptica en estos últimos años del milenio. Naturalmente tal estado de la cuestión se complementa con otros que anteriormente han ido haciéndose en reuniones científicas y publicaciones de la especialidad, de ahí que hayamos escogido como margen los últimos años y de ahí también que se ofrezca una relación sucinta de lo que se echa en falta. No se puede pedir exhaustividad en tan corto espacio, de manera que necesariamente tendremos que proceder de forma selectiva, a veces por el desconocimiento de algunas obras referidas a la materia que nos ocupa.

\section{Congresos y actas}

El mundo de los congresos, reuniones, seminarios, etc. ha seguido un ritmo apreciable, y ha producido buen número de actas, resúmenes, publicaciones de jornadas, etc. Muy destacables son por su propia magnitud los celebrados en Madrid por la Asociación Internacional de Hispanistas (1998) y en Münster por la Asociación Internacional del Siglo de Oro (1999), ambos se convocan cada tres años y reúnen a buen número de profesores y estudiosos, y cristalizan en publicaciones de varios volúmenes. 
Han seguido los congresos sobre edición y anotación, cuyas dos primeras entregas fraguaron en sendos libros publicados por las editoriales Castalia y Támesis; el tercero se ha dedicado a los textos coloniales y se ha editado con el título Edición y anotación de textos coloniales hispanoamericanos a cargo de Ignacio Arellano y J. A. Rodríguez Garrdo (Madrid-Pamplona: Iberoamericana-Universidad de Navarra, 1999).

El Congreso de Jóvenes Filólogos reunió en La Coruña a buen grupo de jóvenes y menos jóvenes en 1996, cuyas intervenciones fraguaron en unas actas tituladas Edición y anotación de textos, a cargo de Carmen Parrilla et. al. (A Coruña: Universidade, 1998).

La literatura medieval ha visto editado el conjunto de ponencias presentadas al Coloquio Internacional La Fermosa Cobertura en un libro titulado precisamente La Fermosa Cobertura: lecciones de literatura medieval (Pamplona: EUNSA, 2000). También la Asociación Hispánica de Literatura Medieval ha editado las actas de su congreso celebrado en Castellón en 1997 en un libro titulado Actes del VII Congrés..., a cargo de Santiago Fortuño Llorens y Tomás Martínez Romero (Castellón: Universitat Jaume I, 1999).

La Universidad de Castilla-La Mancha organizó un seminario dedicado a los poetas menores de los Siglos de Oro, entre los que se encontraban Polo de Medina, Rioja, Baltasar de Medinilla y otros.

La Sociedad de Literatura Española del siglo XIX ha editado su coloquio primero, en unas actas que se titulan Del romanticismo al realismo, a cargo de Luis F. Díaz Larios y Enrique Miralles (Barcelona: Universitat, 1998).

En 1997 se organizaron varios eventos relacionados con Cervantes, entre ellos el Tercer Congreso Internacional de la Asociación de Cervantistas (CINDAC), cuyas Actas acaban de salir impresas en grueso volumen (Palma de Mallorca: Universitat, 1998), a cargo de Antonio Bernat; también el congreso de "Locos amenos», igualmente a cargo de A. Bernat y J. M. Casasayas (Salamanca-Palma de Mallorca: Universidad de Salamanca-Universitat de les Illes Balears, 2000).

Como no podía ser menos, el 98 ha suscitado buen número de encuentros de eruditos y especialistas, como las conferencias que se publicaron con el título de Paisaje y figura del 98, a cargo de Carlos Seco Serrano et al. (Madrid: Fundación Central Hispano, 1997) o el congreso El 98 y la pérdida de las colonias celebrado en Ottawa en 1998, después editado como número extraordinario de la Revista Canadiense de Estudios Hispánicos (1999). De la misma forma, autores concretos como Lorca o Valle han tenido un tratamiento especial. 


\section{Estado de la cuestión en materia de literatura en España}

Otros congresos o seminarios igualmente productivos se han llevado a cabo sobre relaciones de sucesos, como el titulado precisamente $L a$ fiesta. Actas del II Seminario de relaciones de sucesos, editado por Sagrario López Poza y Nieves Pena Sueiro en la Universidad de La Coruña (La Coruña: SIELAE, 1999).

\section{Homenajes}

Esta importante fuente recopilatoria de estudios se ha visto aumentada por el dedicado al profesor Díez Taboada, Estudios de literatura española de los siglos XIX y XX, a cargo de José Carlos de Torres y Cecilia García Antón (Madrid: CSIC, 1998), también el dedicado a Patrick Gallagher, A Lifetimes reading: Hispanic essays for Patrick Gallagher, a cargo de Don W. Cruickshank (Dublin: University College, 1999) y a don Emilio García Gómez, Lírica popular, lírica tradicional: lecciones en homenaje a -.--, editado por Pedro M. Piñero Ramírez (Sevilla: Universidad, 1998). De la misma manera el profesor Deyermond ha recibido un merecido libro de homenaje titulado The medieval mind: Studies in honour of -.. (London: Tamesis, 1997).

\section{Colecciones y editoriales}

Existen buen número de colecciones de textos, algunas de reciente creación, otras que llevan ya tiempo en el mercado y han supuesto la edición de numerosas obras. Es el caso de la serie de Espasa Nuevos Clásicos Castellanos, que ha tenido el acierto de ofrecer ediciones magníficas dedicadas a Timoneda, Valle Inclán (muy poco editado, si no es por las ediciones de Austral) y otros. Esta misma editorial ha lanzado una serie de obras completas, donde se han fijado definitivamente textos de Berceo, Machado, Miguel Hernández, Buero y otros autores. De la misma forma, la colección austral ha incorporado nuevos títulos a su catálogo, algunos muy interesantes, precedidos ahora de un cuidado prólogo y una anotación a la altura de la obra en cuestión. En otras ocasiones recupera un texto ya editado, que ahora aparece con prólogo y apéndice didáctico al final. Textos tan dispares como las Claves líricas de Valle-Inclán, Peribáñez o una antología de la poesía de los siglos de Oro se pueden seguir leyendo con placer a un precio muy asequible en esta colección fundamental para las letras españolas 
Clásicos Castalia y Letras Hispánicas de las editoriales Castalia y Cátedra, respectivamente, han seguido prestando sus buenos servicios a la comunidad filológica, por cuanto han continuado con la edición de textos importantes y de otros que sin serlo menos estaban mucho menos editados. Por no citar sino algunos de los últimos, baste señalar la aparición en estas series de libros como el dedicado a Vicente Medina (Díez de Revenga). De la misma manera, la editorial Crítica continúa con los números de la Biblioteca Clásica, y entre otros ha editado Los pazos de Ulloa (Ermitas Penas, 2000) o el El diablo cojuelo (Ramón Valdés, 1999).

La Biblioteca Castro, que tanto servicio presta por cuanto supone la recuperación de algunos textos verdaderamente difíciles, se ha seguido ampliando con libros como los Coloquios de Arce de Otalora o la Philosophía moral, de Pérez de Moya, junto con otros apenas editados modernamente y otros que sí cuentan con numerosas ediciones en el mercado, como las obras de Cervantes o Galdós. Recientemente se han editado las Obras completas de un narrador y crítico tan polifacético como Juan Antonio Gaya Nuño (Consolación Baranda, 1999).

En el capítulo de las nuevas colecciones hay que llamar la atención sobre la que se titula «Medio maravedí», que dirige el profesor Antonio Bernat, de la Universidad de las Islas Baleares, y que edita Olañeta. En un formato muy atractivo se ofrecen algunos títulos muy curiosos como Sonetos sobre los XVI modos del Aretino, traducidos y con estudio preliminar (Edición de Pablo Luis Ávila. Palma de Mallorca: Olañeta, 1999); o el Arte de bien morir medieval, precedido de un clarificador estudio también de Francisco Gago (Palma de Mallorca: Olañeta, 2000). El SEMYR, Seminario de Estudios Medievales y del Reancimiento, de Salamanca, ha editado entre 1998 y 1999 cuatro volúmenes de diferente materia, que van desde la teoría sobre la traducción en la época clásica (María Isabel Hernández González, 1998) a El arte de la poesía: el cancionero (María Isabel Toro Pascua, 1999), pasando por otros libritos dedicados a parodias universitarias o artes de poesía y prosa. De la misma forma, Ignacio Arellano dirige la reciente Biblioteca Áurea Hispánica, que la editorial Iberoamericana-Vervuert está empezando a editar, y que cuenta con un buen número de libros ya dedicados a diferentes aspectos como la Bibliografía del teatro breve (De la Granja-Lobato), a la edición de textos como El alcalde de Zalamea o a estudios sobre aspectos varios como la poesía toledana (Madroñal, 1999) o la obra cervantina (Zimic). Desde Italia nos llega la sugerente colección «Agua y Peña» que ha editado libros tan interesantes como la edición crítica del Jardín de hermosura de Urrea (a cargo de Monica von Wunster. Luca: Mauro Baroni, 1996) y otros. 
La editorial Arco Libros sigue en su línea, filológicamente impecable, con la edición del corpus médico en que vienen trabajando Nieves Sánchez y María Teresa Herrera, que cuenta ya con algunos títulos fundamentales, como el Lilio de medicina de Gordonio o la Sevillana medicina y que contará en breve con la obra Diez privilegios para mujeres embarazadas de Alonso de los Ruizes de Fontecha, y con otros títulos diferentes.

Peter Lang viene editando desde hace tiempo estudios y textos de literatura española, no hace mucho nos llegaba La silva curiosa de Medrano (Alcalá Galán New York, 1998); también los Cantores del Corpus Christi, que se debe a la profesora Elizabeth Wilhelmsen (New York, 1996) y que recoge poetas de todas las épocas, desde la Edad Media hasta nuestros días, que han tratado en sus versos el tema eucarístico. La editorial Visor, especializada en poesía, ha dedicado también algunos de sus títulos a libros imprescindibles en materia filológica, como la edición facsímil de Vocabulario de refranes, de Correas, prologada por el profesor Víctor Infantes o la edición crítica del Cancionero de Baena, que se debe a los especialistas Dutton y González Cuenca.

Por su parte, el Seminario de Estudios Hispánicos de Madison ha editado también obras medievales y de los Siglos de Oro, con el rigor que le caracteriza. De manera que podemos encontrar otros cancioneros y libros fundamentales. En el campo de los cancioneros hay que mencionar la continua labor del profesor Labrador, editor entre otros del Cancionero sevillano de Nueva York (Sevilla: Universidad de Sevilla, 1998) y otros y de la magnífica tarea levada a cabo por el desaparecido recientemente Brian Dutton, cuando publicó su magna obra de recopilación en siete volúmenes sobre el cancionero medieval.

La editorial Reichenberger, aunque mayoritariamente dedicada al teatro de los Siglos de Oro, ha destinado también algunos títulos y series a la prosa y poesía, incluso ha dado a conocer textos difíciles como el inédito Libro de los buenos proverbios, que se debe al profesor Weiner; pero también obras de Jorge de Montemayor y otras de muy interesante aportación y otras referidas al siglo XX como la obra de Juventino Caminero, Poesía española del siglo XX: capítulos esenciales (1998).

Otra editorial fundamental para los estudios de literatura española es Tamesis, que ha editado no solo buenos conjuntos de documentos para la historia del teatro, también estudios como el de Jeremy Robbins dedicado a las academias, Love poetry of the Literary Academies in te reigns of Philip IV and Charles II (1998), que viene a completar 
los ya clásicos de King y Sánchez y otros sobre novela sentimental española.

Las editoriales provinciales, que no siempre distribuyen demasiado bien sus libros, publican estudios y ediciones importantes, así la Diputación de Sevilla ha editado la Obra crítica de Cansinos-Assens (A. González Troyano, 1998), en una colección titulada Biblioteca de Autores Sevillanos y en otra la obra de Héctor Brioso Santos, Sevilla en la prosa de ficción del Siglo de Oro (1998). En Huesca el Instituo de Estudios Altoaragoneses ha publicado El lugar de un hombre, de Sender (Donatella Pini, 1998). La Diputación de Badajoz ha editado el libro El Oeste dorado: una mirada literaria a la Extremadura del Siglo de Oro, que se debe a Miguel Á. Teijeiro Fuentes (Badajoz, 1999).

Por desgracia hay que lamentar la desaparición de otras colecciones de textos clásicos que tanto servicio han prestado como la que la editorial Taurus ha mantenido hasta hace algunos años o Clásicos Planeta, a la que tan magníficas ediciones de textos se deben, algunos de difícil localización, como las obras completas de Mena o Santillana.

\section{Ediciones electrónicas}

En la actualidad disponemos de buen número de ediciones electrónicas, bancos de textos literarios y no literarios de todas las épocas, pero especialmente de las que no tienen que ver con los últimos años, por el consabido problema de los derechos de autor. Un servidor muy interesante en este orden de cosas es el denominado Parnaseo de la Universidad de Valencia, que ha puesto a disposición de todos los investigadores el profesor José Luis Canet. Dedicado específicamente a literatura medieval y del renacimiento, Parnaseo es mucho más que eso, por cuanto supone una de las mejores puertas de entrada para conectar con todos los estudios y ediciones de literatura española, así como con bases de datos dedicadas a su investigación. Pero aparte de eso, podemos encontrar textos teatrales del XVI, obras de Timoneda o Lope de Rueda, otras de Villegas, Castillejo, etc. El GRISO de la Universidad de Navarra también ofrece una serie muy interesante de textos, sobre todo referidos a sus líneas de edición prioritarias, como son los autos de Calderón, la comedia burlesca, Tirso y Quevedo. Además, pone a disposición de los investigadores un interesante banco de notas, que han de ayudar mucho en la anotación textual a los siglodoristas. Indudablemente la iniciativa más sorprendente en este orden de cosas se debe a la Universidad de Alicante, que ha puesto hace poco en la 
red un servidor denominado centro virtual cervantes, donde se cuelgan más de dos mil textos de literatura española de todas las épocas. Siglos poco representados tradicionalmente en lo que se refiere al esfuerzo editorial - como el XVIII- encuentran aquí un desarrollo significativo, solo empobrecido por la falta de datos editoriales.

\section{Corpus}

Cosa diferente, pero igualmente importante, en la presencia de corpus en español que se basan en ediciones de textos literarios, y en especial el CORDE (Corpus Diacrónico del Español) y el CREA (Corpus de Referencia del Español Actual), que la Real Academia Española tiene ya a disposición de todos los investigadores en la red. Ambos Corpus son complementarios, el primero abarca desde los inicios del idioma hasta 1974 y el segundo arranca desde 1975 hasta el 2000. Ambos se basan en ediciones de textos literarios y no literarios (que se reparten de diferente manera) y en algún caso han supuesto la edición de obras que no se volvían a editar desde que se imprimieron.

\section{Listas de distribución}

Existen foros internacionales permanentes, dedicados al estudio de la literatura española, las que se denominan listas de distribución, algunas moderadas: Mediber es probablemente la más importante en lo que se refiere a la literatura medieval; Orfeo se dedica a la poesía de los siglos de Oro, Gnomo tiene como campo de acción la literatura del XIX y, muy especialmente, la figura de Bécquer. La lista Reder se dedica a la difusión del exilio republicano y también a su literatura; siglo-xviii a todo lo que tiene que ver con este siglo en España y América; tecnotrad y traducción a lo que afecta a la traducción y su historia, etc.

\section{Otros formatos}

Las publicaciones en cederrom también se van haciendo importantes, no en vano podemos conseguir por este medio textos y bases de datos muy significativas. La fundación Clásicos Tavera ha dedicado varios a recoger en este formato lo más representativo de nuestra historia 
lingüística y literaria. Probablemente la más importante, en lo que se refiere a la literatura medieval española es la titulada ADMITE, proyecto dirigido por el profesor Marcos Marín (Universidad Autónoma de Madrid), que ha tenido ya una actualización y que cuenta con un copioso conjunto de textos medievales, junto con otros programas diseñados pro el propio responsable para ayuda y edición de textos, junto con la base de datos Philobiblon, que es una herramienta fundamental de localización de ejemplares de obras medievales en todas las bibliotecas.

Existen en la actualidad bases de datos significativas al servicio de la investigación: como TESEO (Ministerio de Educación y Cultura), ISBN (Ministerio de Educación y Cultura), la primera dedicada a las tesis doctorales leídas en universidades españolas en los últimos veinticinco años, la segunda a los libros en venta en nuestro país.

Existen igualmente revistas filológicas en la red, que suponen la existencia de estudios y ediciones de textos de todas las épocas, como por ejemplo la titulada Lemir, que cuenta ya con cuatro números, en los que se pueden encontrar ediciones de difícil acceso, como la Sponsalía de amor y sabiduría, de Luis Hurtado de Toledo, y estudios muy bien documentados, cuyas anotaciones a pie de página también se pueden consultar. Otras revistas ofrecen sus índices en las diferentes páginas que existen, es el caso de La Perinola, dedicada a Quevedo, y que se publica anualmente en papel, pero cuyo índice de contenidos se muestra en la página del ya citado GRISO de la Universidad de Navarra.

\section{Centenarios}

A La Celestina se le han dedicado diversos congresos, como el que tuvo lugar en el año de su centenario en Salamanca, Toledo, Talavera y La Puebla de Montalbán. También se ha llevado a cabo una exposición de libros y objetos artísticos titulada «El Jardín de Melibea» (Burgos, 2000). Cinco Siglos de «Celestina»: Aportaciones interpretativas, ed. de Rafael Beltrán y José L. Canet. Valencia: Universitat de València, 1997. Monografías interesantes que tocan aspectos particulares de la obra o su autor son también las de Emilio de Miguel, La "Celestina» de Rojas. (Madrid: Gredos, 1996) o Adelia Gasbarrone, La tradizione primitiva de "La Celestina»: collazione e studio di Valencia, 1518. (Roma: Università degli studi di Roma «La Sapienza», 1995-96), más dedicada a la herencia americana el de Roberto González Echevarría, La prole de Celestina. Continuidades del Barroco en las literaturas española e 
hispanoamericana. (Madrid: Colibrí, 1999) y a sus ilustraciones el de Germana Piantone, Le illustrazioni antiche de "La Celestina» di Fernando de Rojas: 1499-1531. (Roma: La Sapienza, 1996).

Los centenarios de Calderón y Gracián van a suponer la edición de obras y estudios, también de estados de la cuestión, como el que prepara la profesora Aurora Egido en la Universidad de Zaragoza.

El año 1997, 450 aniversario del nacimiento de Cervantes, concitó la presencia de diferentes actos organizados para celebrarlo y la edición de las actas correspondientes. De la misma manera el año 1998 ha supuesto la celebración de todo tipo de encuentros dedicados a la generación así denominada y ha propiciado la edición de obras, especialmente de Lorca y Valle, pero también de otros poetas y narradores nacidos en esa fecha, aunque en mucha menor medida.

\section{Facsímiles}

Con motivo de los centenarios se ha promovido la edición de facsímiles, como el que se ha hecho de la primera edición de la comedia (Salamanca, 1999) o de la recién descubierta edición completa de Zaragoza, 1507 (Toledo, Antonio Pareja, 1999); o de la de Valencia, 1514 (Valencia, Institución Alfonso el Magnánimo, 1999). Todas con interesantes estudios preliminares de destacados especialistas en la obra. También la exposición «El Jardín de Melibea» (Burgos, 2000) ha editado un catálogo en el que constan varios estudios y una bibliografía celestinesca.

Otras obras muy interesantes de apoyo a la labor filológica, como las bibliotecas Nova y Vetus de Nicolás Antonio, acaban de aparecer en facsímil (Madrid: Visor, 1996), el mismo autor nos llega también en facsímil su Censura de historias fabulosas (Madrid: Visor, 1999).

\section{Autores y épocas}

Se han dedicado monografías y ediciones verdaderamente importantes a autores fundamentales de nuestra literatura, como es el caso de los Romances de Góngora, en edición monumental de Carreira (Barcelona: Quaderns Crema, 1998) o la recopilación de trabajos que titula Gongoremas del mismo (Barcelona: Península, 1998) o de los Estudios sobre Góngora (Córdoba: Ayuntamiento-Real Academia, 1996), con importantes aportaciones sobre el poeta debidas a diversos autores; Que- 
vedo cuenta en la actualidad con una especie de "summa» que se debe a Pablo Jauralde y lleva por título Francisco de Quevedo y Villegas (1580-1645) (Castalia, 1999), que supone un planteamiento de todos los datos que se tienen sobre la vida y la obra del gran autor, el cual ha merecido también la publicación de una magnífica bibliografía que se debe a la profesora Isabel Pérez Cuenca, premio de bibliografía de la Biblioteca Nacional. De la misma manera, la poesía amorosa de Quevedo ha merecido la atención crítica del profesor Fernández Mosquera en un libro editado por Gredos. Cervantes ha seguido contando con importantes aportaciones, especialmente dedicadas a rescatar su obra con una importante anotación. De ahí que hayan aparecido diversas ediciones, como las que han publicado en diferentes medios Florencio Sevilla y Antonio Rey (Centro de Estudios Cervantinos, Alianza Editorial); por fin ha salido la primera edición crítica del Quijote, dirigida por el profesor Francisco Rico (Crítica-Instituto Cervantes, 1998), con abundantísima y fiel información de todo tipo, desde la textual a la literaria o puramente enciclopédica el Quijote ha conocido recientemente una versión latina (Antonio Peral Torres. Alcalá de Henares: Centro de Estudios Cervantinos, 1998). Los estudiosos de Lope de Vega han visto por fin publicadas sus Rimas en una edición crítica excelente, que se debe al profesor Felipe Pedraza (Universidad de Castilla-La Mancha).

Pero también algunos de los menos conocidos han merecido un estudio parcial en el libro Oscura turba de los más raros escritores españoles (Zaragoza: Xordica, 1999), que no estudia a los más raros, pero sí a algunos contemporáneos poco conocidos y merecedores de más atención crítica.

El maestro López Estrada ha estudiado un texto medieval en su libro Poética de la frontera andaluza (Antequera, 1424) (Salamanca: Universidad, 1998). Un estudio más basado en el ámbito románico es el editado por Valeria Bertolucci, Carlos Alvar y Stefano Asperti, Le letterature medievali romanze darea iberica (Roma-Bari: Laterza, 1999).

También don Manuel Alvar ha recopilado diversos trabajos en un volumen titulado Nebrija y otros estudios sobre la Edad de Oro (Madrid: CSIC, 1997). El siglo XVI y en especial la polémica erudita entre los comentaristas de Garcilaso ha tenido continuación en la obra de Bienvenido Morros, Las polémicas literarias en la España del siglo XVI: a propósito de Fernando de Herrera y Garcilaso de la Vega (Barcelona: Q \& C, 1998); sobre el autor en particular y el descubrimiento de una relación amorosa hasta ahora ignorada se ha publicado un documentado libro. 


\section{Estado de la cuestión en materia de literatura en España}

La vida y escritos de Eugenio Gerardo Lobo han merecido la atención crítica de José María Escribano Escribano en su libro Biografía y obra de Eugenio Gerardo Lobo (Toledo: IPIET, 1996).

La literatura del XIX, especialmente su vertiente anticlerical ha sido analizada en la obra de José Luis Molina Martínez, Anticlericalismo y literatura en el siglo XIX (Murcia: Universidad, 1998). En su relación con la filosofía y el pensamiento ha encontrado particular análisis en el libro Pensamiento y literatura en España en el siglo XIX: Idealismo, Positivismo, Espiritualismo, a cargo de Sylvie Baulo, Yvan Lissorgues y Gonzalo Sobejano (Toulouse: PUM, 1998).

Autores realistas como Galdós han visto reeditadas sus obras, como los Ensayos de crítica literaria (Laureano Bonet. Barcelona: Península, 1999). Y a la influencia del romanticismo en este movimiento literario se ha dedicado el libro Asimilaciones y rechazos: presencias del romanticismo en el realismo español del siglo XIX, bajo la dirección de Lieve Behiels y Maarten Steenmeijer (Amsterdam-Atalanta: Rodopi, 1999).

A esa etapa anterior a la guerra se dedica la obra de Juan Cano Ballesta, Literatura y tecnología: las letras españolas ante la revolución industrial (1890-1940) (Valencia: Pre-textos, 1999).

A los hombres del 98 y el 14 ha dedicado Andrés Trapiello su libro Los nietos del Cid: la nueva edad de oro de la literatura española (Barcelona: Planeta, 1997). Por su parte, la evolución de la poesía española desde esta generación a la posguerra se ha visto analizada en el libro de Antonio Vilanova, Poesía española del 98 a la posguerra (Barcelona: Lumen, 1998). A la primera de las dos generaciones se ha dedicado el ibro El 98 se paseó por el Callejón del Gato, a cargo de José Belmonte Serrano y Pedro Guerrero Ruiz (Murcia: Ayuntamiento, 1999). Algunos autores han visto reeditadas sus obras, como las Lecturas españolas, Clásicos y modernos, Al margen de los clásicos, de Azorín, prologado por Carlos Clavería (México: Porrúa, 1999).

Las vanguardias han merecido también una sugerente antología, acompañada de una bibliografía imprescindible para adentrarse en su estudio, que se deben a Harald Wentzlaff-Eggebert, Las vanguardias literarias en España: bibliografia y antología crítica. Madrid: Iberoamericana-Vervuert, 1999. También Biruté Ciplijauskaité ha dedicado su atención crítica a la relación entre vanguardia y Generación del 27 en un libro titulado De signos y significaciones (Barcelona: Anthropos, 1999).

Los autores del 27, particularmente los poetas, se han visto analizados en un libro de Miguel García-Posada, Acelerado sueño: memoria 
de los poetas del 27 (Madrid: Espasa, 1999). Antonio A: Gómez Yebra ha publicado su obra En torno al 27: estudios sobre José Moreno Villa, Emilio Prados, Manuel Altolaguirre, José María Hinojosa, Jorge Guillén (Málaga: Centro cultural Generación del 27, 1998). Otro libro dedicado a la influencia gongorina es el de Francisco Narbona, Sevilla, Góngora y la generación del 27 (Sevilla: Real Academia Sevillana, 1997). A la lengua poética de esta generación se dedica la obra de Derek Harris, Metal Butterflies and Poisonous Lights: the language of Surrealism in Lorca, Alberti, Cernuda and Aleixandre (Fife: The Barracks, 1998). $\mathrm{Y}$ a otros autores menos conocidos, sobre los que López Rubio llamara ya su atención en su discurso de ingreso en la Real Academia Española, se ha dedicado el libro Vanguardia y humorismo: la otra generación del 27, a cargo de $\mathrm{M}^{\mathrm{a}}$ Luisa Burguera Nadal y Santiago Fortuño Llorens (Castellón: Universitat Jaume I, 1998). Ediciones modernas de poetas del 27 se pueden señalar bastantes, particularmente fecunda ha sido la labor en torno a Lorca, con motivo de su centenario; también Alberti ha visto reeditadas sus Prosas encontradas, edición del Robert Marrast (Barcelona: Seix Barral, 2000).

La evolución poética desde el 27 a nuestros días ha merecido el estudio de José María Balcells, De Jorge Guillén a Antonio Gamoneda (León: Universidad, 1998).

La literatura del exilio se ha visto reconocida en diversos estudios como el de Michael Ugarte, Literatura española en el exilio: un estudio comparativo (Madrid: Siglo XXI, 1999), y el de Emilia de Zuleta, más dedicado a Argentina, Españoles en Argentina: el exilio literario de 1936 (Buenos Aires: Atril, 1999). José Rodríguez Richart ha publicado también un libro titulado Emigración española y creación literaria (Madrid: CDEE, 1999).

Luis García Montero ha dedicado una subjetiva monografía a la poesía española, El sexto día: historia íntima de la poesía española (Madrid: Debate, 2000). Juan Malpartida ha publicado La perfección indefensa: ensayos sobre literaturas hispánicas del siglo XX (México: FCE, 1998), donde estudia pormenorizadamente la poesía de Claudio Rodríguez, entre otros nombres. Las poesía de posguerra sigue viva en antologías como ala de López de Abiada, Martínez de Mingo y Pérez Escohotado, Poemas memoriables: antología consultada y comentada (1939-1999) (Madrid: Castalia, 1999). De la misma manera Ricardo Senabre ha publicado Claves de la poesía contemporánea (de Bécquer a Brines) (Salamanca: Almar, 1999).

Poetas como José María Valverde han visto editada su Obra completa (David Medina. Madrid: Trotta, 1998), también José Hierro ha sido 
objeto de varios libros, entre ellos A José Hierro: encuentros, edición de Domingo Nicolás (Almería: Instituto de Estudios Almerienses, 1999) y el de Joaquín Benito de Lucas, Vida y poesía de José Hierro (Madrid: Universidad Autónoma, 1999).

Se ha recopilado y editado por vez primera un conjunto de estudios del eruditos e investigador José F. de Montesinos, que lleva por título Entre Renacimiento y Barroco, edición al cuidado de Pedro Álvarez de Miranda (Granada: Fundación García Lorca, 1997).

\section{Géneros y temas}

En lo que toca al libro en sí, hay que señalar la existencia de obras singulares, como la de Vicente Bécares Botas, Arias Montano y Plantino: el libro flamenco en la España de Felipe II (León: Universidad, 1999).

En lo referido a la teoría de la literatura hemos de contar con libros como el de José María Pozuelo Yvancos y Rosa $\mathrm{M}^{\mathrm{a}}$ Aradra, Teoría del canon y literatura española (Madrid: Cátedra, 2000). Sobre poética Juan Carlos Rodríguez ha publicado sus Dichos y escritos, con nota de F. Díaz de Castro (Madrid: Hiperión, 1999). Pedro Ruiz Pérez ha dedicado también a estos asuntos el libro El espacio de la escritura: en torno a una poética del espacio del texto barroco (Bern: Lang, 1996). La estética literaria posterior a la guerra ha merecido el estudio de Sultana Wahnon, La estética literaria de la posguerra: del fascismo a la vanguardia (Amsterdam-Atlanta: Rodopi, 1999).

La prosa castellana ha merecido el análisis de Fernando Gómez Redondo en un libro titulado Historia de la prosa medieval castellana (Madrid: Cátedra, 1998), cuyo volumen primero se dedica a la «creación del discurso prosístico». A la presencia de América en la prosa de los Siglos de Oro ha dedicado una obra Héctor Brioso Santos, América en la prosa literaria española de los siglos XVI y XVII (Huelva: Diputación, 1999).

$\mathrm{Al}$ estudio de la literatura de academias, siempre tan sugerente, se dedica la obra de Pasqual Mas i Usó, Academias valencianas del Barroco: descripción y diccionario de poetas (Kaseel: Reichenberger, 1999) y la ya citada de G. Robbins.

Al tema del sueño Teresa Trueba Gómez dedica su obra El sueño literario en España: consolidación y desarrollo del género (Madrid: Cátedra, 1999). Otros temas particulares, como la presencia de América en la poesía han merecido un estudio como el de Mercedes Cobos, 
Las Indias Occidentales en la poesía sevillana del Siglo de Oro (Sevilla: Universidad, 1997).

El cuento español ha sido recogido en una antología de Arturo Ramoneda, Antología del cuento español (Madrid: Alianza, 1999), que abarca desde la Edad Media a nuestros días.

Los libros de caballería tienen por fin la edición que merecen y van viendo a la luz en el Centro de Estudios Cervantinos obras capitales, según el escrutinio cervantino. También algunos repertorios utilizadísimos en la época clásica, como el que se debe a fray Baltasar de Vitoria, titulado Teatro de los dioses de la gentilidad (1620), que se publicó en varias partes y que tanto auxilió a nuestros escritores clásicos para suministrar erudición con la que componer sus obras. En lo referido al mundo de los emblemas hay que aplaudir la aparición de una obra fundamental, como es la Enciclopedia de emblemas, que se debe a los profesores John Cull y Antonio Bernat, con la colaboración de Antonio Fernández Coca, que ordena por fin y de manera sistemática todo este complejo mundo de imágenes y los más diferentes motivos literarios o no.

Si no propiamente enciclopédicos, sí es interesante reseñar la aparición de ediciones que afectan a herramientas fundamentales para el estudio filológico, como son las del Tesoro de Covarrubias (no superada por la nueva de Camarero en Castalia) o la edición facsímil de $\mathrm{Au}$ toridades que la Academia ha puesto a disposición de los investigadores gratuitamente en su página en la red. También es interesante el facsímil del diccionario de Rosal y del de Terreros.

La literatura erótica ha conocido alguna reunión científica y ha visto también editados estudios como el titulado El cortejo de Afrodita: ensayos sobre literatura hispánica y erotismo, a cargo de Antonio Cruz Casado (Málaga: Universidad, 1997). Al mismo asunto se dedica el libro Erotismo en las letras hispánicas: aspectos, modos y fronteras, a cargo de los profesores F. Márquez Villanueva y Luce López-Baralt (México: El Colegio de México, 1995). En lo que se refiere a la literatura actual Eva Legido-Quigley ha publicado ¿Qué viva Eros?: de la subversión posfranquista al «thanatismo» posmoderno en la narrativa erótica de escritoras españolas (Madrid: Talasa, 1999).

La literatura de y para mujeres se ha visto beneficiada en algunos casos. Así contamos con estudios como el de Lydia Masanet, La autobiografía femenina española contemporánea(Madrid: Fundamentos, 1998).

También la literatura de la guerra civil ha visto publicarse libros como el titulado Literatura en la guerra civil 1936-1939, a cargo de José Esteban y Manuel Llusia (Madrid: Talasa, 1999). 
La última literatura también ha merecido la atención de obras como la titulada Literaturas de España: 1975-1998. Convergencias y divergencias, bajo la dirección de Andreu van Hooft Comajuncosas (Amsterdam: Rodopi, 1998).

Mucha más atención se ha prestado al género costumbrista, con libros como el de los profesores Joaquín Álvarez Barrientos y Alberto Romero Ferrer, Costumbrismo andaluz (Sevilla: Universidad de Sevilla, 1998) o el de M. I. Jiménez Morales, La literatura costumbrista en la Málaga del siglo XIX (Málaga: Diputación Provincial, 1996). Por su parte, $\mathrm{M}^{\mathrm{a}}$ de los Ángeles Ayala ha estudiado el mismo asunto referido a las colecciones en su libro Las colecciones costumbristas (1870-1885) (Alicante: Universidad de Alicante, 1993). Al costumbrimo aragonés se ha dedicado el $\mathrm{V}$ curso sobre lengua y literatura en Aragón, que fraguó en un libro titulado Localismo, costumbrismo y literatura popular en Aragón, a cargo de José-Carlos Mainer y José $\mathrm{M}^{\mathrm{a}}$ Enguita (Zaragoza: Institución Fernando el Católico, 1999). A la literatura regionalista navarra se dedica el libro de Iñaki Iriarte López, Tramas de identidad: literatura y regionalismo en Navarra (1870-1960) (Madrid: Biblioteca Nueva, 2000).

La literatura fantástica romántica y posterior ha merecido el estudio al cuidado de Jaume Pont, Narrativa fantástica en el siglo XIX (Lleida, Milenio, 1997).

La novela sentimental ha recibido la atención crítica que se merece en la recopilación de Joseph J. Gwara y E. Michael Gerli, Studies on the Spanish sentimental romance (1449-1550) (London: Tamesis, 1997).

La picaresca y similares han visto reeditarse una vez más los grandes títulos que la componen: Lazarillo, Buscón (Fernando Cabo. Barcelona: Crítica, 1998), y algunas menos conocidas como la curiosa Andanzas del Buscón don Pablos por México y Filipinas, de Vicente Alemany, que ha editado Celsa C. García Valdés (Pamplona: Universidad de Navarrra, 1998).

La novela bizantina cuenta desde hace unos años con nuevos estudios fundamentales, como el que se debe al investigador J. González en Gredos o el de Emila Deffis de Calvo, Viajeros, peregrinos y enamorados: la novela española de peregrinación del siglo XVII (Pamplona: EUNSA, 1999).

La novela histórica del romanticismo cuenta también con el estudio de Franklin García Sánchez, Tres aproximaciones a la novela histórica española (Ottawa: Dovehouse, 1993).

La novela realista ha merecido también análisis, alguno tan curioso como el titulado El doble silencio del eunuco: poéticas sexuales de la 
novela realista según Clarín, que se debe a Andrés Zamora Juárez (Madrid: Fundamentos, 1998).

Y la novela de posguerra con obras de conjunto como la de Daniel Gier, La Castilla rural en la narrativa de posguerra (Valladolid: Junta de Castilla y León, 1997). Al punto de vista narrativo de los republicanos se dedica el estudio de Gemma Mañá Delgado et. al. La voz de los náufragos: la narrativa republicana entre 1936 y 1939 (Madrid: Ediciones de la Torre, 1997).

$\mathrm{Al}$ género de la novela rosa le ha dedicado una monografía María Teresa González, Corín Tellado, medio siglo de novela de amor (Oviedo: Pentalfa, 1998) y a la más actual Vance R. Holloway la que lleva por título El posmodernismo y otras tendencias de la novela (1967-1995) (Madrid: Fundamentos, 1999). Un intento de catalogación de «La novela mundial» se debe a $\mathrm{M}^{\mathrm{a}}$ Carmen Santamaría Barceló, La novela mundial. Catalogación (Madrid: CSIC, 1997).

En materia de poesía, Margit Frenk ha terminado su nuevo Corpus de la lírica antigua, que editará el Colegio de México y que supone una versión muy aumentada del que hace años publicara la editorial Castalia, junto con el Suplemento al mismo publicado poco después por la misma editorial. La misma editorial ha recuperado los villancicos y ensaladas de un poeta nacido en España pero que vivió en Nueva España, como es Fernán González de Eslava. Pero la literatura de tradición oral y, en particular, la poesía ha sido estudiada también por José Manuel Pedrosa en su obra Tradición oral y escrituras poéticas en los siglos de Oro (Oiartzun: Sendoa, 1999).

$\mathrm{Al}$ estudio de la poesía en sus diferentes géneros se han dedicado obras como el muy documentado de Maria Paz Díez Taboada, La despedida: estudio de un subgénero lírico (Madrid: CSIC, 1998). A la épica culta ha dedicado el profesor José Lara Garrido su libro Los mejores plectros: teoría y práctica de la épica culta en el Siglo de Oro. (Málaga: Universidad, 1999). La poesía religiosa ha merecido una tesis voluminosa, que se ha materializado en cuatro tomos y se debe a $L a$ poesía a lo divino.

La poesía renacentista también cuenta con un nuevo estudio, el que se debe a Ingacio Navarrete, Los huérfanos de Petrarca: poesía y teoría en la España renacentista (Madrid: Gredos, 1997).

La poesía del siglo XX ha sido estudiada en un libro titulado La isla de los ratones: poesía española del medio siglo (Santander: Obra Social Caja de Cantabria, 1998), que recoge diversos textos de Juan Ramón, Zamora Vicente y el que así se titula de Ricardo Gullón. También José Olivio Jiménz ha visto editado recientemente su librto Poetas 
contemporáneos de España y América (Madrid: Verbum, 1998). A la poesía de la primera posguerra ha dedicado Raquel Medina Bañón su libro Surrealismo de la poesía española de la posguerra (1939-1950) (Madrid: Visor, 1997).

El profesor Jorge Urrutia ha recogido y editado recientemente $E l$ modernismo. Apuntes de curso (1953), de Juan Ramón (Madrid: Visor, 1999). Al movimiento postista dedica una monografía $\mathrm{M}^{\mathrm{a}}$ Isabel Navas Ocaña, El postismo (Cuenca: El toro de Barro, 2000).

Disponemos ahora de nuevos catálogos de bibliotecas, como el de la Fundación Lázaro Galdiano (Juan Antonio Yeves, Madrid, 1999) o el de manuscritos de la Biblioteca de Palacio; cuya versión de impresos se ha publicado también recientemente. También las bibliografías y tipobibliografías han visto acrecentado el número de títulos con la aparición de obras como las recientemente dedicadas a la imprenta en Madrid, Salamanca o Alcalá de Henares, editado por Arco Libros. De la misma forma, el profesor Aguilar Piñal continúa su Bibliografía de autores españoles del siglo XVIII (Madrid, CSIC) con la reciente aparición de un volumen dedicado a impresos anónimos.

\section{Falta}

En el capítulo de las cosas que se echan de menos, hemos de señalar la ausencia de inventarios de bibliotecas españolas y extranjeras, de archivos particulares y públicos, cuyos documentos aún se desconocen en su mayoría y que se podrían preservar de diferentes peligros mediante la utilización de modernos métodos de reproducción, como se ha hecho con el Archivo de Indias. Señalemos, por ejemplo, la recién trasladada biblioteca Bartolomé Mach, ahora en Palma de Mallorca, con importantes autógrafos de Góngora y otros autores.

Falta igualmente la edición de esos libros raros que apenas encontramos, peros que se muestran muy útiles para el esclarecimiento y la anotación de otros textos. Tratados sobre las más diferentes materias, incluso obras literarias no tan usuales, merece la pena que se editen de forma conveniente y que su texto quede fijado ya para ir abasteciendo a generaciones de filólogos, que han de partir de ellos para construir nuevos estudios e interpretaciones.

Falta también la recopilación de textos de apoyo, tales como la obra de Cotarelo recientemente editada en facsímil Bibliografía de las controversias sobre la licitud del teatro en España, con estudio e índices de José Luis Suárez (Granada: Universidad, 1997). El ejemplo 
seguido por la Universidad de Granada debería servir a otras editoriales para rescatar de esta manera estudios fundamentales sobre la lírica o la narrativa de todas las épocas. De la misma forma que urge la traducción de otros textos importantes que todavía tenemos que seguir leyendo en su edición y lengua originales, cuando son muy difíciles de encontrar ya. Sobran los ejemplos concretos en esta ocasión.

Falta completar obras básicas como la Bibliografía de Simón Díaz (CSIC) o la Cronología de la literatura española, que todavía carece del tomo dedicado a los siglos de Oro, aunque sí tiene el resto.

Los autores de menor «importancia», tradicionalmente relegados a ser una cita en nota en los manuales, requieren también un tratamiento especial, no porque se pretenda descubrir con ellos valores a la altura de los más grandes ingenios, sino porque son las piezas que completan un mosaico que no podrá ser apreciado en su totalidad hasta que no se posean. 